\title{
Performance of an ionomer blend-nanocomposite as an effective gas barrier material for organic devices $\uparrow$
}

\begin{abstract}
Sindhu Seethamraju, ${ }^{a}$ Praveen C. Ramamurthy ${ }^{\star a b}$ and Giridhar Madras ${ }^{a}$
A new, flexible, gas barrier material has been synthesized by exfoliating organically modified nano-clays (MMT) in the blends of Surlyn (PEMA) using a copolymer of vinyl alcohol (EVOH) and demonstrated as a gas barrier material. The materials were characterized by Fourier transform infra red (FTIR) and UV-visible spectroscopy, differential scanning calorimetry (DSC), thermo-gravimetric analysis (TGA) and tensile studies. The oxygen and water-vapor permeabilities of the fabricated films were determined by calcium degradation test and a novel permeability setup based on cavity ring down spectroscopy, respectively. Hierarchical simulations of these materials helped us to understand the effect of intermolecular interactions on diffusivities of oxygen and water molecules in these materials. Schottky structured poly(3-hexylthiophene) based organic devices were encapsulated with the fabricated films and aging studies were carried under accelerated conditions. Based on permeability test results and accelerated aging studies, the fabricated PEMA/EVOH/MMT composites were found to be effective in decreasing the permeabilities for gases by about two orders of magnitude and maintaining the lifetime of organic devices.
\end{abstract}

Received 9th December 2013 Accepted 6th February 2014

DOI: $10.1039 / c 3 r a 47442 a$

www.rsc.org/advances

\section{Introduction}

Barrier materials are required for encapsulation in various applications ranging from packaging of food and pharmaceuticals to photovoltaics in order to protect them from detrimental effects of moisture and oxygen. The permeability of the vapor/ gas through the barrier material determines the lifetime of the packed product. ${ }^{1-3}$ In applications such as organic photovoltaics, light emitting diodes, thin film solar cells, liquid hydrogen storage, etc., flexible, lightweight, ultra high gas barrier materials are needed. ${ }^{4,5}$ For such applications, oxygen transmission rates (OTR) $<10^{-5} \mathrm{~cm}^{3}$ per $\mathrm{m}^{2}$ per day per bar and water vapor transmission rates (WVTR) $<10^{-6} \mathrm{~g}$ per $\mathrm{m}$ per day are required. Though inorganic materials such as glass offer high barrier to gases, they are not suitable for flexible, roll to roll processing and lightweight applications. ${ }^{6}$ Polymers are flexible and easily processable but have poor barrier properties. Therefore, a secondary phase and/or inorganic component is added as filler/ layer to the neat polymer for achieving high gas barriers.

Inorganic oxides on polymeric substrates in a layered architecture have been used to achieve the ultra high barrier requirement by following complex deposition techniques such as plasma enhanced chemical vapor deposition and atomic/molecular layer deposition. $^{7-9}$ These techniques are not economical and thus difficult to commercialize. Moreover, problems like nano level pinhole mediated permeation, crystal boundary effects, formation of dark spots are evident in layered materials. ${ }^{\mathbf{1 0}}$ Therefore, in order to avoid such problems, direct reinforcement of polymers with 
inorganic/organic nano components by simple processing techniques is being extensively investigated. ${ }^{\mathbf{1 1}}$

Various inorganic nano fillers such as silica, ${ }^{12}$ alumina, ${ }^{13}$ zinc-oxide, ${ }^{14}$ clays, ${ }^{15}$ boron nitride,${ }^{16}$ etc., have been previously used for improving the barrier properties of polymeric materials. The presence of electrostatic, ionic, hydrogen bonding and van der Waals interactions would result in better compatibility between the two blended components. ${ }^{17}$ The geometry of the filler material and the availability of free volume for the permeation of gas molecules through the material influences the resultant barrier property. ${ }^{18,19}$

Poly(ethylene-co-methacrylic acid) (PEMA) is a self healable ionomer ${ }^{\mathbf{2 0 , 2 1}}$ where permeation of gases is diffusion dominant while poly(vinyl alcohol-co-ethylene) (EVOH) exhibits good oxygen barrier property. Blending these two polymers can result in the formation of ester linkage and hydrogen bonds decreasing the available free volume for permeation and the inter-segmental motion of the polymer molecules. ${ }^{22}$ The addition of modified nano-clays to neat $\mathrm{EVOH}$ will increase the compactness of the composite by decreasing the free volume due to the compatibility between the matrix and filler. Further, addition of inorganic platelets like clays would result in increased diffusion pathways through the matrix. ${ }^{23}$ From our previous studies on the effect of the addition of inorganic phases such as zinc oxide ( $\mathrm{ZnO})$, alumina $\left(\mathrm{Al}_{2} \mathrm{O}_{3}\right)$ and nano clays on water vapor barrier, modified clay was found to provide better barrier due to the increased tortuous pathway for the permeant. ${ }^{13,14,23} \mathrm{ZnO}$ can form reactive traps for permeating $\mathrm{H}_{2} \mathrm{O}$ with the alcohol groups on polymer. However, the solubility of the polymer will be affected due to the presence of $-\mathrm{OH}$ groups which increases the permeability of the system. Therefore, in this work, a system with diffusion dominant regime based on Surlyn was chosen which exhibited improved moisture barrier with the addition of $\mathrm{EVOH}$ due to the reduction in free volume. ${ }^{22}$ In order to improve the barrier properties further, modified clay has been chosen. All the three components, Surlyn, EVOH and modified montmorillonite clays (MMT) cannot be blended into single system as it results in phase separation and aggregation. Therefore, the composite of $\mathrm{EVOH}$ and modified clay fabricated by solution casting was blended with Surlyn by melt extrusion to achieve the synergistic effect of both the blend and composite materials.

Apart from designing materials with ultra-high gas barrier properties, development of techniques for determining ultralow permeability measurements is also important. Techniques based on infrared spectroscopy, ${ }^{24}$ coulometry, ${ }^{25}$ mass spectroscopy, ${ }^{26}$ tritium based radioactive decay, ${ }^{27}$ gravimetry, ${ }^{28}$ calcium degradation $^{29}$ and electrochemical methods ${ }^{30}$ are available for determination of WVTR. Of all these techniques, only the tritium based radioactive decay and calcium degradation test can be used for determining the ultra low permeabilities of WVTR $\sim 10^{-6} \mathrm{~g}$ per $\mathrm{m}^{2}$ per day. However, tritium based technique is neither economical nor environmental friendly. Calcium degradation test cannot be used for long term studies due to the constraint on the thickness of the calcium film deposited. Moreover, the validity of calcium degradation test is dependent on the resistivity of calcium, which is constant only above a film thickness of $100 \mathrm{~nm}$. Below $100 \mathrm{~nm}$, the resistivity of calcium varies with thickness due to the presence of grain boundary effects. ${ }^{31}$ One mole of calcium reacts with two moles of water but only with half mole of oxygen. In this work, calcium degradation test was used to determine OTR only.

In order to determine WVTR, a novel technique based on cavity ring down spectroscopy (CRDS) method ${ }^{32}$ was developed for determining the permeabilities of barrier materials. This setup is capable of measuring WVTR varying from $10^{-6}$ to $100 \mathrm{~g}$ per $\mathrm{m}^{2}$ per day. It is based on direct measurement of the number of permeant water molecules through the barrier films. This patented technique ${ }^{33}$ has been further used to characterize the fabricated blend composite barrier films in this work.

Molecular structure and dynamics studies help in the fundamental understanding of the system and its properties. Polymer nanocomposites, because of their hierarchical structures, require simulations at various time and length scales to correlate the atomistic phenomena at the macro level. ${ }^{34}$ Several studies have investigated the diffusivities of oxygen and water in various polymers such as rubbery polymers, ${ }^{35,36}$ poly(ether-etherketone), ${ }^{37}$ silicones, ${ }^{38}$ etc. Therefore, a hierarchical modeling approach based on molecular dynamics (MD) and dissipative particle dynamics (DPD) has been developed to ensure the understanding of the diffusion properties of water and oxygen molecules through the blend composites developed in this study.

The first objective of this study was to fabricate and characterize the blend composite of Surlyn/EVOH/modified MMT. The second objective was to determine the barrier property based on the new CRDS based permeability setup for measurement of WVTR and study the effect of interactions from simulations. Finally, the composites were tested for their suitability for encapsulating organic devices based on accelerated aging experiments.

\section{Experimental details}

\subsection{Materials}

PEMA (9 wt\% methacrylic acid, neutralized with zinc salt (0.5$5 \%)$, copolymer of vinyl alcohol and ethylene, EVOH $(38 \%$ ethylene) and montmorillonite (MMT) (clay surface modified with $15-35 \mathrm{wt} \%$ of octadecylamine and $0.5-5 \mathrm{wt} \%$ of aminopropyltrimethoxysilane) were obtained from Sigma Aldrich Ltd (St. Louis, MO). Dimethylsulfoxide (DMSO), tetrahydrofuran (THF), chlorobenzene and carbon tetrachloride $\left(\mathrm{CCl}_{4}\right)$ solvents of $\sim 99.5 \%$ purity were obtained from S.D. Fine Chem. (India) and were used without any further purification. Poly(3-hexylthiophene) (P3HT) was purchased from Rieke Metals Inc. (USA). A curable epoxy resin, Lapox L12, was obtained from Atul Industries, Ltd. (India).

\subsection{Processing}

Modified clays are platelets of aluminosilicates separated by organic functional groups. ${ }^{39}$ Better dispersion and exfoliation of the clays in polymer can be achieved by swelling the clays initially in polymer solution. Direct melt mixing of modified clays with Surlyn will not result in the complete exfoliation of 
clay platelets due to the lack of favourable interactions between the two components. ${ }^{40}$ Therefore, in the present study, modified clays were initially allowed to swell and intercalate in the EVOH copolymer, which was then melt mixed with Surlyn. Thus, the processing of the composite blend consisted of two steps: solvent casting and melt mixing.

Initially, DMSO was used to dissolve $\mathrm{EVOH}$ at $80{ }^{\circ} \mathrm{C}$ by continuous stirring. The wt\% of clay added is lower than the percolation threshold for intercalation $(12 \%$ for $\mathrm{EVOH}$ and modified MMT), above which transition occurs due to flocculation. Modified MMT was then dispersed in EVOH solution at 5 and $10 \mathrm{wt} \%$ for $24 \mathrm{~h}$ and subjected to sonication for $15 \mathrm{~min}$. Mechanical stirring and sonication help in swelling of MMT layers and their exfoliation, respectively.

The dispersions of EVOH/modified MMT were casted on a Teflon ${ }^{\mathrm{TM}}$ coated mold $100{ }^{\circ} \mathrm{C}$ to obtain composite films. These composite films were completely dried of the residual solvent by subjecting to vacuum at $30 \mathrm{~mm} \mathrm{Hg}$ for $24 \mathrm{~h}$. The neat EVOH and composite films were further cut into pieces and blended with various wt\% of PEMA in Haake mini screw extruder with counter rotating screws at $100 \mathrm{rpm}$ for $10 \mathrm{~min}$ at $190{ }^{\circ} \mathrm{C}$ under nitrogen purging. The first letter $i$, in the designation $B i j$ represents the composition of the blends of PEMA and EVOH. B0, B1, B2 and B3 correspond to 100, 95, 90 and 80\% of PEMA in the blend composite. The second letter $j$ represents the \% of modified MMT in the blend composites. The final compositions of the blend composites obtained (in wt\%) (PEMA, EVOH, modified MMT) were designated as B00 $(100,0,0), \mathrm{B} 10(95,5,0)$, B11 (95, 4.75, 0.25), B12 (95, 4.5, 0.5), B20 (90, 10, 0), B21 (90, $9.5,0.5), \mathrm{B} 22(90,9,1), \mathrm{B} 30(80,20,0), \mathrm{B} 31(80,19,1)$ and B32 $(80,18,2)$ and are summarized in Table 1 . The wt\% of EVOH was confined to $20 \%$ in the blend so that the matrix would be pertained to diffusion dominant regime of Surlyn. The samples were classified as $\mathrm{B} i j$ where $i$ represents $\mathrm{EVOH}$ and $j$ represents MMT. $i, j=0$ implies the absence of the corresponding component in the blend/composite. The extruded blends were fabricated into films by compressing with a force of $20 \mathrm{~kg} \mathrm{~cm}^{-2}$ for $1 \mathrm{~min}$ at $200{ }^{\circ} \mathrm{C}$. The thickness of the films was $\sim 50 \pm 5 \mu \mathrm{m}$.

\subsection{Material characterization}

ASTM D1505 standard was followed to construct the density gradient column for determining the density of all the fabricated films. Various mixtures of THF $\left(890 \mathrm{~kg} \mathrm{~m}^{-3}\right)$ and $\mathrm{CCl}_{4}$ $\left(1590 \mathrm{~kg} \mathrm{~m}^{-3}\right)$ with different densities were slowly poured along the side wall of the column. ${ }^{22}$ Then the films were slowly released into the column and their positions were noted after settling.

Fourier transform infrared (FTIR) and UV-visible characterizations of all the fabricated films were carried out using IR spectrometer (Thermo-Nicolet 6700) from 400 to $4000 \mathrm{~cm}^{-1}$ at $4 \mathrm{~cm}^{-1}$ interval and UV-visible spectrometer (Perkin Elmer Lambda-35) from 240 to $1100 \mathrm{~nm}$ at $1 \mathrm{~nm}$ interval, respectively. Thermal transition and melting properties of all the compositions were determined from differential scanning calorimetry (DSC) (Mettler Toledo DSC $822^{\mathrm{e}}$ ). Heating and cooling rates of $5{ }^{\circ} \mathrm{C} \min ^{-1}$ were used during the two consecutive cycles from -60 to $220{ }^{\circ} \mathrm{C}$ and 220 to $-60^{\circ} \mathrm{C}$, respectively, under the flow of nitrogen. Thermal degradation studies were conducted with heating at $10 \mathrm{~K} \mathrm{~min}^{-1}$ with a TG/DTA instrument (Perkin Elmer S11 Pyris Diamond) under nitrogen.

Tensile analysis was carried out for not less than 3 samples from each composition. They were characterized on a micro UTM (Mecmeisin), with a load cell of $10 \mathrm{kN}$ at $25 \mathrm{~mm} \mathrm{~min}^{-1}$ in accordance with Type V, ASTM D882-12 standard. The X-ray analysis of the modified MMT and blend composite films was carried out in grazing mode at an incidence of $0.5^{\circ}$ using Rigaku $\mathrm{X}$-ray diffractometer at a scan rate of $1^{\circ} \mathrm{min}^{-1}$ from $0.5^{\circ}$ to $5^{\circ}$. A humidity chamber (Kaleidoscope, KEW/PHC-80), was used for controlling humid environmental conditions during moisture absorption, calcium degradation, CRDS based WVTR measurement and accelerated device aging experiments. Water vapor sorption studies were carried by hanging the films at 95\% $\mathrm{RH}$ at $35{ }^{\circ} \mathrm{C}$ for $48 \mathrm{~h}$.

\subsection{Calcium based permeability test}

Degradation of a sealed thin film of calcium was used to determine the OTR through the barrier films. OTR was determined by measuring the change in resistance of the calcium film with time under controlled oxygen conditions. ${ }^{41}$ Calcium of density $(\partial)$ was thermally deposited at the center $(l \times b=1 \mathrm{~cm} \times$ $1 \mathrm{~cm})$ onto a cleaned glass slide $(l \times w=2 \mathrm{~cm} \times 2 \mathrm{~cm})$. The $200 \mathrm{~nm}$ thick calcium film is connected on either side with thermally deposited $300 \mathrm{~nm}$ thick aluminium electrodes. The glass slide with calcium was then sealed with the barrier film

Table 1 Thermal, mechanical and water vapor absorption properties for all the films

\begin{tabular}{|c|c|c|c|c|c|c|c|}
\hline $\begin{array}{l}\text { Sample (PEMA : } \\
\text { EVOH : modified } \\
\text { MMT) (in wt } \% \text { ) }\end{array}$ & $\begin{array}{l}\text { Order-disorder } \\
\text { transition } \\
\text { temp. }\left({ }^{\circ} \mathrm{C}\right)\end{array}$ & $\begin{array}{l}\text { Melting temp. } \\
\text { of PEMA } \\
\left({ }^{\circ} \mathrm{C}\right)\end{array}$ & $\begin{array}{l}\text { Onset temp. of } \\
\text { degradation } \\
\text { (at } 5 \% \text { wt loss) }\left({ }^{\circ} \mathrm{C}\right)\end{array}$ & $\begin{array}{l}\text { Ultimate tensile } \\
\text { strength } \\
(\mathrm{MPa})\end{array}$ & $\begin{array}{l}\text { Elongation } \\
\text { at break } \\
(\%)\end{array}$ & $\begin{array}{l}\text { Modulus of } \\
\text { elasticity } \\
(\mathrm{MPa})\end{array}$ & $\begin{array}{l}\text { Water vapor } \\
\text { absorption } \\
\text { (wt\%) in } 48 \mathrm{~h}\end{array}$ \\
\hline B00 $(100: 0: 0)$ & 45.3 & 97.3 & 400.5 & $9.2 \pm 0.3$ & $140 \pm 2$ & 105 & 1.41 \\
\hline B10 (95: $5: 0)$ & 44.8 & 97.9 & 382.2 & $9.3 \pm 0.4$ & $93 \pm 4$ & 164 & 1.33 \\
\hline B20 (90:10:0) & 44.7 & 97.4 & 373.4 & $10.3 \pm 0.4$ & $84 \pm 3$ & 235 & 0.88 \\
\hline B30 $(80: 20: 0)$ & 44.7 & 97.6 & 365.8 & $8.2 \pm 0.2$ & $48 \pm 8$ & 226 & 0.46 \\
\hline B11 (95: $4.75: 0.25)$ & 44.7 & 97.1 & 387.0 & $9.4 \pm 0.1$ & $115 \pm 4$ & 124 & 1.07 \\
\hline B21 (90: $9.5: 0.5)$ & 44.7 & 97.4 & 342.1 & $9.1 \pm 0.2$ & $76 \pm 5$ & 201 & 0.31 \\
\hline B31 (80: $19: 1)$ & 44.7 & 97.3 & 327.9 & $9.3 \pm 0.3$ & $64 \pm 5$ & 260 & 0.17 \\
\hline B12 (95 : $4.5: 0.5)$ & 45.3 & 97.2 & 369.3 & $7.5 \pm 0.6$ & $51 \pm 7$ & 145 & 0.48 \\
\hline B22 (90: $9: 1)$ & 45.3 & 97.3 & 363.2 & $10.0 \pm 0.3$ & $89 \pm 3$ & 195 & $<0.01$ \\
\hline B32 (80: $18: 2)$ & 45.8 & 97.3 & 356.3 & $9.2 \pm 0.1$ & $91 \pm 5$ & 262 & $<0.01$ \\
\hline
\end{tabular}


using epoxy. Thermal depositions and sealing were carried inside the Mbraun glove box with inert atmosphere $\left(\mathrm{H}_{2} \mathrm{O}<5\right.$ ppm, $\left.\mathrm{O}_{2}<10 \mathrm{ppm}\right)$. The sealed device ${ }^{22}$ was placed in a oxygen chamber as shown in Fig. 1(a) (at ambient temperature with moisture content $<100 \mathrm{ppm}$ ) OTR experiments. When oxygen permeates through the sealed barrier film, calcium starts reacting forming its oxide increasing the resistance of calcium film. The increase in resistance $(R)$ with time $(t)$ is continuously monitored using a digital multimeter. Oxygen $\left(M_{\mathrm{O}_{2}}=32\right)$ permeated through the barrier film is calculated using eqn (1).

$$
\text { OTR }=\left[-\left(\frac{1}{2}\right) \frac{M_{\mathrm{O}_{2}}}{M_{\mathrm{Ca}}} \partial \rho\left(\frac{l}{b}\right) \frac{\mathrm{d}\left(\frac{1}{R}\right)}{\mathrm{d} t}\right]\left(\frac{R_{\mathrm{o}} T}{P}\right)
$$

$M_{\mathrm{Ca}}=40$ and $\rho, R_{\mathrm{o}}, T$ and $P(=1$ bar $)$ correspond to the resistivity of calcium, gas constant, temperature and pressure, respectively. Due to the dependence of the calcium resistivity on its film thickness, only thickness higher than $100 \mathrm{~nm}$ is used for determining WVTR/OTR.

\subsection{CRDS based WVTR measurement}

A new setup based on CRDS has been developed to measure WVTR. CRDS is generally used for the determination of concentration of trace analyte species in a flow gas. ${ }^{42}$ It works on the principle of extinction of light pulse of a particular wavelength captured in a cavity due to reflectivity losses and absorption by the analyte species present in the cavity. The time taken for the intensity of light to decay down to zero in the test cell is measured by CRDS. ${ }^{\mathbf{4 3 4 4}}$ Hence, this technique is capable of measuring concentrations up to parts per trillion (ppt) level of the contaminant/analyte present in the test cell. The patented setup devised with CRDS for measuring WVTR of the barrier films as low as $10^{-6} \mathrm{~g}$ per $\mathrm{m}^{2}$ per day was used for determining WVTR of the blend composite films.

CRDS (Tiger optics, HALO+ 500 ATM Moisture Analyzer) with a sensitivity of $\pm 0.01 \mathrm{ppb}$ and an accuracy of $4 \%$ of reading in the operating range $20-500$ ppm $\mathrm{H}_{2} \mathrm{O}$ has been used in the setup. Humidity and temperature sensors (EXTECH, RH520) with an accuracy of $\pm 3 \%$ for $\mathrm{RH}$ and $\pm 1{ }^{\circ} \mathrm{C}$ for temperature, a mass flow meter (Honeywell, AWM5200 series) in the range of 0-5 LPM, and humidity chamber were used in the setup. All the sample lines were constructed using 316L stainless steel and 10 Ra surface finished copper tubing and were connected with $\mathrm{VCR}^{\mathrm{TM}}$ fittings. Leak rate was tested throughout the setup and was found to be below $2 \times 10^{-8} \mathrm{mbar} \mathrm{L} \mathrm{s}^{-1}$ for $\mathrm{N}_{2}$.

The schematic for the CRDS based permeability setup is shown in Fig. 1(b). The test chamber consists of two flanges between which the sample to be tested is placed. The bottom flange is purged with nitrogen at $500 \mathrm{~cm}^{3} \mathrm{~min}^{-1}$ with the outlet connected to the inlet of CRDS test cell. The outlet line from the CRDS is connected to a flow meter, to measure the flow rate of the purge gas $\left(\mathrm{N}_{2}\right)$. The top flange, i.e., the other side of the test sample is pumped with humid air from the humidity chamber. The outlet of this line is connected to the humidity sensor to continuously monitor relative humidity. The water vapor that permeates through the test sample from humid air into nitrogen gas is analyzed and the $\mathrm{H}_{2} \mathrm{O}$ concentration is measured with time by the CRDS. The pressure in the test cell is maintained at 1.12 bar.

Initially $\mathrm{N}_{2}$ gas was purged on either side of the sample for stabilization of CRDS reading as well as to remove the absorbed/ adsorbed moisture in the flow lines. After attaining steady state, water vapor flow was started on the other side of the film at $30{ }^{\circ} \mathrm{C}$ and $93 \pm 2 \% \mathrm{RH}$. The steady value is considered as the base line value $\left(C_{\mathrm{o}}\right)$. The concentration $\left(C_{\mathrm{t}}\right)$, reading from CRDS, starts increasing once the $\mathrm{H}_{2} \mathrm{O}$ molecules permeate through the

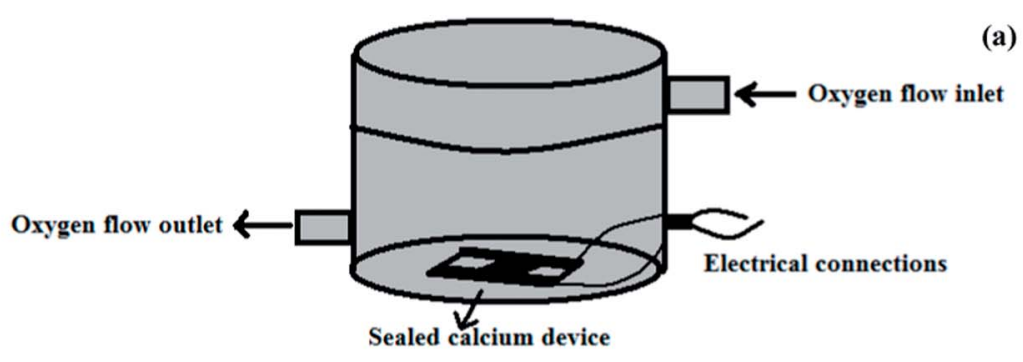

(a)

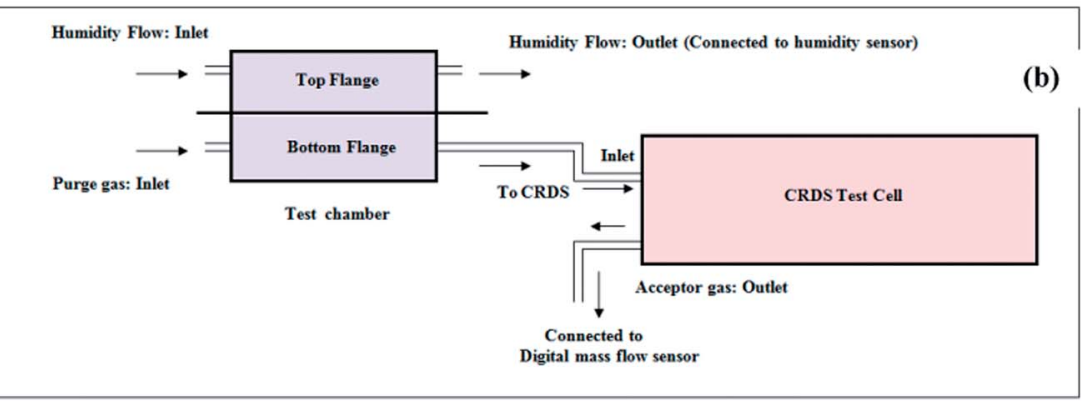

Fig. 1 Schematic for permeability setup for determining (a) OTR by calcium degradation test and (b) WVTR using cavity ring down spectroscopy. 
film (from humid air flow) and enter the other side (to purge flow). Thus, the increase in the concentration from the base line, gives the water vapor permeability (WVTR) following eqn (2), where $N_{\text {flow }}$ is the nitrogen flow rate and $A$ is the effective area of the test sample exposed to humid air.

$$
\mathrm{WVTR}=\frac{\left(C_{\mathrm{t}}-C_{\mathrm{o}}\right) \times\left(18 \times N_{\text {flow }}\right)}{\left(A \times 10^{9}\right)}
$$

\subsection{Accelerated aging experiments}

Schottky structured devices were fabricated using P3HT as the active organic material. P3HT was dissolved in chlorobenzene and was spin coated on to ITO coated glass slides at $1000 \mathrm{rpm}$ for $60 \mathrm{~s}$. All the devices were annealed at $125{ }^{\circ} \mathrm{C}$ for $10 \mathrm{~min}$ prior to aluminium electrode deposition. Then the devices were encapsulated with the blend and composite films using epoxy sealing at the edges. ${ }^{22}$ The devices were then placed in accelerated conditions of $95 \% \mathrm{RH}$ and $35{ }^{\circ} \mathrm{C}$ for aging studies. Current-voltage $(J-V)$ characteristics were measured using a source meter (Keithley, 2420C) at various time intervals.

\subsection{Simulation details}

The main aim of simulating the blend composite system was to study the time evolution of the system of particles and to determine the diffusion properties of gases $\left(\mathrm{O}_{2}\right.$ and $\left.\mathrm{H}_{2} \mathrm{O}\right)$ in these materials. The molecular structures of Surlyn, EVOH, modified MMT, $\mathrm{H}_{2} \mathrm{O}, \mathrm{O}_{2}$ and beads representing them and for molecular as well as dissipative particle dynamics simulations were generated using Materials studio 6.0 (Accelrys Inc.) (MS). The energetic interactions for PEMA, EVOH, octadecylamine (ODA) and aminopropyltrimethoxysilane (APTMS) during MD simulations were acquired using COMPASS forcefield. ${ }^{45}$ Nonbonded energy interactions were determined using Ewald summation method with a convergence limit of $10^{-5} \mathrm{kcal} \mathrm{mol}^{-1}$ throughout the MD simulations.

Polymer chains of PEMA and EVOH with chain lengths of 34 and 20, respectively, were built using the MS Build module following Markov transition probability scheme (given in Fig. S1(a) and (b) $\dagger) .{ }^{46}$ They were constructed in such a way that PEMA chain contained $9 \mathrm{wt} \%$ of methacrylic acid and EVOH contained $62 \mathrm{~mol} \%$ of vinyl alcohol with chirality inversion and flip probabilities set to values of 1.0 and 0 , respectively. Similarly, organic functional molecules ODA and APTMS (Fig. S2(a) and (b) $\dagger), \mathrm{H}_{2} \mathrm{O}, \mathrm{O}_{2}$ were constructed. All the polymers and small molecules were geometrically optimized and energetically minimized following the smart algorithm, using series of steepest descent, conjugate gradient and quasi Newton-Raphson methods. ${ }^{47-49}$ The convergence limit of the energy minimization step was set to $2.0 \times 10^{-5} \mathrm{kcal} \mathrm{mol}^{-1}$. Conformers for PEMA, EVOH, ODA and APTMS were searched for using Boltzmann jump distribution over $10^{5}$ conformers for lowest energy conformations. ${ }^{50}$ The conformations with least energies were further used in next steps. PEMA, EVOH, ODA and APTMS molecules were allowed for molecular dynamics simulated anneal (MDSA) dynamics. ${ }^{51}$ Following the MDSA protocol, each system was equilibrated for energy by NPT (constant pressure) molecular dynamics (MD) and NVT (constant volume) at $308 \mathrm{~K}$ and 1 bar for $10 \mathrm{ps}$. Finally, the MDSA protocol ended with NVE (constant energy) dynamics for $10 \mathrm{ps}$. The equilibration simulation runs were carried with $Q$-ratio of 0.1 in Nose ensemble control method for temperature control, ${ }^{52}$ with a decay constant of 0.1 ps using Berendsen control method for the controlling the pressure, ${ }^{53}$ and with a time step of $1.00 \mathrm{fs}$.

The charges on the atoms of ODA and APTMS were determined from $\mathrm{MS} \mathrm{DMol}^{3}$ calculations. Single point quantum mechanical energy calculations were used for electrostatic potential fitting using the PBE exchange-correlation functional ${ }^{54}$ with the limit of tolerance at $10^{-6}$ Ha with double numerical plus polarization 4.4 basis set. ${ }^{55}$ The MMT periodic structure with CEC of 148 mequiv./100 g was built using MS Crystal builder module with the crystallographic coordinates for pyrophyllite clays (monoclinic lattice, $c 2 / m$ ) and exchanging sufficient atoms of aluminium with magnesium. ${ }^{56}$ The charges were given to the atoms of MMT according to experimental values. ${ }^{57}$ The potassium ions in the gallery spacing between clay layers were removed to obtain negatively charged MMT layers. The built unit crystal (Fig. S3(a) $\dagger$ ) was extended further to obtain a super cell (Fig. S3(b) $\dagger$ ) of dimensions $20 \AA \times 20 \AA \times 20 \AA$. Then the MMT basal surfaces are covered with charged ODA and APTMS molecules sufficient for maintaining charge neutrality of the modified MMT and to obtain similar clay as used experimentally.

The amorphous cell module of MS was used to build a cell system with 3 platelets of modified MMT from the constructed MMT super cell at $308 \mathrm{~K}$ with the simulation box open in one direction perpendicular to the basal surface of clays for adjustment of gallery spacing (i.e., clays were allowed to move only in $Z$ direction). The unit cell was relaxed by subjecting it to NPT (constant pressure) molecular dynamics (MD) for $50 \mathrm{ps}$ followed by $N V T$ (constant volume) at 1 bar and $308 \mathrm{~K}$ with time step of 0.1 fs. ${ }^{58}$ As simulation proceeds with time, the ODA and APTMS molecules cover the surface of MMT due to the favorable interactions and the final gallery spacing was found to be $\sim 18 \AA$. The obtained modified MMT (Fig. S4(a) $\dagger$ ) from the final NVT MD simulation was considered as the optimized clay structure similar to experimental clay and further used in final MD and DPD simulations for acquiring the energy and diffusion properties, respectively.

Two platelets of modified MMT from the previously modified MMT structure were used along with the polymeric chains of PEMA and EVOH in a unit cell to simulate the blend composite. The PEMA and EVOH chains were placed in the gallery spacing between the platelets. Following MDSA protocol, the system was allowed to equilibrate using 5 anneal cycles and 5 heating ramps with mid cycle temperature at $1000{ }^{\circ} \mathrm{C}$ and a convergence limit of $2 \times 10^{-4} \mathrm{kcal} \mathrm{mol}^{-1} \AA^{-1}$. Then the system was subjected to NVT dynamics at $308 \mathrm{~K}$ after which the gallery spacing was found to be $53 \AA$ (Fig. S4(b)†). The increase in gallery spacing was similarly observed experimentally after processing of the blend composite. A single platelet of modified MMT along with the polymeric chains PEMA and EVOH from the final equilibrated cell were inserted in another cell and subjected to $50 \mathrm{ps}$ of $N V T$ MD simulations followed by $N V E$ dynamics for obtaining interaction energies between the components of the system. 
The binary interaction energies between any two components of the system were determined by removing other components from the final, energy minimized simulation cell and subjecting to energy of mixing calculations. Thus the obtained total energies and non bonded energies were further used for calculating the repulsive interaction DPD parameters required for mesoscale simulations.

The DPD system for the blend nanocomposite consists of E1, $\mathrm{E} 2, \mathrm{P} 1, \mathrm{D} 1, \mathrm{D} 2, \mathrm{~A} 1, \mathrm{~A} 2, \mathrm{~m}, \mathrm{H}_{2} \mathrm{O}$ and $\mathrm{O}_{2}$ beads. The beads E1, E2, $\mathrm{P} 1$ correspond to ethylene, vinyl alcohol and methacrylic acid monomer unit constituents of the polymers PEMA and EVOH. D1 and D2 and A1 and A2 represent head-tails for the ODA and APTMS groups used for modification of MMT. The $\mathrm{H}_{2} \mathrm{O}$ and $\mathrm{O}_{2}$ beads refer to water and oxygen molecules, respectively. The bead $\mathrm{m}$ corresponds to MMT platelet. All the beads were calculated for their characteristic dimension according to the bead volumes as determined by the Connolly algorithm. ${ }^{59}$ The DPD systems were constructed by mapping the atomistic simulation energies on to mesoscale system and following a similar approach used previously. ${ }^{\mathbf{6 0}}$

The DPD simulation box was set with dimensions $40 \times 40 \times$ 80 for all the compositions (B00, B10, B20, B30, B11, B21, B31, B12, B22, B32) with a density of $\rho=3$ using $\sim 3000$ beads (Fig. S5(a)-(d) $\dagger$ ). A repulsive wall has been used to represent MMT platelet and covered with beads of $m$ type and are fixed in position. Hence, non bond energy of the bead $\mathrm{m}$ is considered zero during simulations. The contributions from beyond binary interactions were neglected in all the energy calculations. The values of self interaction energies $\left(E_{i j}, i=j\right)$ are calculated from their equilibrium non bonded energies $\left(E_{\mathrm{nb}}\right)$ and the binary interaction energies $\left(E_{i j}, i \neq j\right)$ are calculated from eqn (3) where $n_{i j}$ represent the number of contacts between the beads.

$$
E_{12}=n_{11} E_{11}+n_{22} E_{22}+2 n_{12} E_{12}
$$

The interaction energies obtained from molecular dynamics simulations after rescaling to DPD energies are given in Table 2 . The bead-bead interaction parameter for the P1-P1 system was set to 25 and the E1-D1 interaction was set to 32 . Thus the energy for P1-P1 interaction and the E1-D1 interaction corresponds to DPD interaction parameters of $\approx 25$ and 32 respectively. Based on this scale, all the other values of interaction parameters were rescaled. The calculated values of DPD interaction parameters for all the bead combinations are given in Table 2 . The values of wall interactions with beads $m$ are set to 50 and with other beads to $>270$. In the DPD cells for blends of PEMA and EVOH (Fig. S5(e) and (f) $\dagger$ ), it can be observed that the methacrylic acid beads (P1) were surrounded by the vinyl alcohol beads (E2) due to the non-bonded, electrostatic interactions between the two components. The DPD simulation was carried out for 1000 DPD time units with a time step of 0.1. From these final DPD simulations, the diffusivities of $\mathrm{H}_{2} \mathrm{O}$ and $\mathrm{O}_{2}$ were determined.

DPD simulation following the modified velocity Verlet algorithm ${ }^{61}$ for integrating the equations of motion of the beads was used to finally determine the diffusivities of water and oxygen through the blend composite systems. The diffusivity of $\mathrm{H}_{2} \mathrm{O}$ and $\mathrm{O}_{2}$ beads through the neat, blend and composite systems during the time 400-500 DPD units was considered for comparison studies.

\section{Results and discussion}

The complex blend composite of Surlyn, EVOH and modified MMT forms a highly interacting matrix as well as tortuous diffusion barrier for permeating molecules. When modified MMT is dispersed in EVOH, the polymer-filler compatibility and the gallery spacing between clay platelets increase. The blending of EVOH/modified MMT composite with Surlyn ionomer further results in electrostatic interactions between the two copolymers. All the interactions in the composite help decreasing the free volume, segmental chain mobility and thereby resulting in reduced permeability. The barrier properties of the composite materials are discussed based on experimental as well as theoretical simulation studies. The figures for PEMA/EVOH blend with composition (in wt\%) 90 : 10, i.e., the B2 $n$ series $(n=0,1,2)$ are separately compared with the neat system (B00) for ease of understanding. The characterization and results for other compositions are given in the ESI. $\dagger$

\subsection{Characterizations}

FTIR analyses for the neat, blend and composite films are given in Fig. 2(a) and S6. $\dagger$ The peaks in the region 474, 523 and $690 \mathrm{~cm}^{-1}$ refer to the presence of aluminosilicates in the composites. $^{62}$ The doublet observed at 729 and $721 \mathrm{~cm}^{-1}$ corresponds to the rocking of methylene in the pendant backbone ${ }^{63}$ and the peak at $1266 \mathrm{~cm}^{-1}$ can be attributed to the stretching vibrations of $\mathrm{C}-\mathrm{O}$ of carboxylic acid groups in the dimers with hydrogen bonds in Surlyn. ${ }^{64}$ These hydrogen bonds help restricting the segmental mobility of polymer chains. The bands in the range of $1420-1500 \mathrm{~cm}^{-1}$ are attributed to the bending of methylene groups. ${ }^{56}$ The peaks at 1587 and $1697 \mathrm{~cm}^{-1}$ correspond to the carboxylates of tetra coordinated $\mathrm{Zn}$ complexes and to the H-bonded carbonyl groups respectively. ${ }^{65}$

The band at $2660 \mathrm{~cm}^{-1}$ corresponds to the stretching of hydrogen bonded -OH of carboxylic acids. The peak intensity decreased with the addition of EVOH due to the interaction of - $\mathrm{COOH}$ of Surlyn with EVOH resulting in a decrease in the availability of $\mathrm{COOH}$ for hydrogen bonding. Similarly, the intensity of the peak increased with the addition of MMT to the blend of PEMA/EVOH due to the decreased number of $-\mathrm{OH}$ groups of $\mathrm{EVOH}$ available for interaction with PEMA (due to interactions between EVOH and MMT). The resultant band between $3000 \mathrm{~cm}^{-1}$ and $2800 \mathrm{~cm}^{-1}$ can be ascribed to the overlap of stretching vibrations of $\mathrm{C}-\mathrm{H}$ in PEMA, EVOH and MMT. The broad peak at $\sim 3300 \mathrm{~cm}^{-1}$ for the blend and composite films can be assigned to the $\mathrm{H}$-bonded -OH groups. ${ }^{66}$ The intensity of this peak increased with the addition of $\mathrm{EVOH}$ and decreased with the addition of MMT and was observed to be highest for the B21 composition. The narrow peaks at 3603 and $3644 \mathrm{~cm}^{-1}$ correspond to the stretching vibrations of non hydrogen bonded $\mathrm{OH}$ groups. This indicates that interactions exist between the EVOH and modified MMT, between PEMA 
Table 2 DPD bead-bead interaction energies rescaled from MD simulations and interaction parameters for all the beads

\begin{tabular}{|c|c|c|c|c|c|c|c|c|}
\hline & E1 & E2 & $\mathrm{P} 1$ & D1 & D2 & A1 & $\mathrm{A} 2$ & $\mathrm{~m}$ \\
\hline \multicolumn{9}{|c|}{$\boldsymbol{E}_{i j}\left(\mathrm{kcal} \mathrm{mol}^{-1}\right)$} \\
\hline E1 & 0.0002 & 0.0577 & 0.0048 & 0.0001 & -0.0190 & 0.0001 & -0.0714 & -0.0687 \\
\hline E2 & 0.0577 & -0.0057 & -0.0700 & -0.0190 & 0.0001 & -0.0714 & 0.0001 & -0.0687 \\
\hline $\mathrm{P} 1$ & 0.0048 & -0.0700 & 0.0099 & 0.1317 & 0.0001 & -0.0038 & -0.0038 & -0.0006 \\
\hline D1 & 0.0001 & -0.0190 & 0.1317 & 0.0480 & 0.0293 & 0.0569 & 0.0569 & -0.0327 \\
\hline D2 & -0.0190 & 0.0001 & 0.0001 & 0.0293 & 0.0142 & 0.0569 & 0.0569 & 0.0001 \\
\hline A1 & -0.0714 & 0.0001 & -0.0038 & 0.0569 & 0.0569 & 0.0052 & 0.0012 & -0.0612 \\
\hline $\mathrm{A} 2$ & 0.0001 & -0.0714 & -0.0038 & 0.0569 & 0.0569 & 0.0012 & -0.0062 & 0.0001 \\
\hline $\mathrm{m}$ & -0.0687 & -0.0687 & -0.0006 & -0.0327 & 0.0001 & -0.0612 & 0.0001 & 0.0000 \\
\hline \multicolumn{9}{|l|}{$a_{i j}$} \\
\hline E1 & 31.90 & 1.00 & 28.64 & 31.99 & 45.64 & 31.99 & 83.07 & 81.14 \\
\hline E2 & 1.00 & 36.13 & 82.07 & 45.64 & 31.99 & 83.07 & 31.99 & 81.14 \\
\hline P1 & 28.64 & 82.07 & 25.00 & 0.15 & 31.99 & 34.78 & 34.78 & 32.49 \\
\hline D1 & 31.99 & 45.64 & 0.15 & 1.00 & 11.14 & 0.50 & 0.50 & 55.42 \\
\hline D2 & 45.64 & 31.99 & 31.99 & 11.14 & 21.92 & 0.50 & 0.50 & 31.99 \\
\hline A1 & 83.07 & 31.99 & 34.78 & 0.50 & 0.50 & 28.35 & 31.21 & 75.78 \\
\hline $\mathrm{A} 2$ & 31.99 & 83.07 & 34.78 & 0.50 & 0.50 & 31.21 & 36.49 & 31.99 \\
\hline $\mathrm{m}$ & 81.14 & 81.14 & 32.499 & 55.42 & 31.99 & 75.78 & 31.99 & 32.07 \\
\hline
\end{tabular}
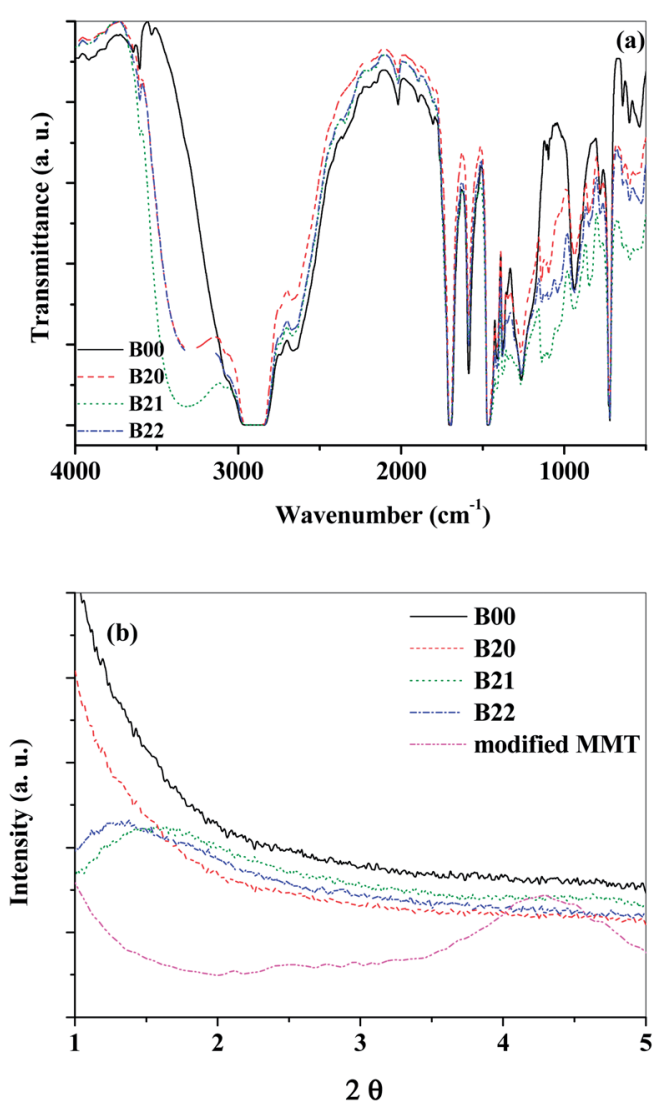

Fig. 2 (a) FTIR spectra and (b) XRD peaks referring to gallery spacing for the neat (B00), blend (B20) and composite (B21, B22).

and $\mathrm{EVOH}$ and are favorable, resulting in compatibility between the components, thereby decreasing the free volume and increasing the density synergistically.

Hence, the densities of fabricated films with different compositions were determined to evaluate the effect of interactions. The densities for the neat, blend and composite films are given in Fig. 3. Neat Surlyn film was observed to have the lowest density of $\sim 930 \mathrm{~kg} \mathrm{~m}^{-3}$. The density of the Surlyn/EVOH blends increased with the addition of EVOH content to the blend and it is observed to be $\sim 960 \mathrm{~kg} \mathrm{~m}^{-3}$ for the B30 composition. Further, with the addition of modified MMT to EVOH, the density of the blends increased up to $972 \mathrm{~kg} \mathrm{~m}^{-3}$, as observed for B32 composition. This suggests the increase in matrix density of Surlyn due to the addition of the two interacting components.

XRD analysis was carried out in order to verify the extent of intercalation of modified MMT in the nanocomposites. The gallery spacing between the modified MMT layers is $\sim 20 \AA$ (Fig. 2(b)). When the modified MMT is blended with polymers, the layers are further separated due to the mechanical stresses during processing of the composites. The organic modifications of the clays help achieving better compatibility between the hydrophobic polymeric and the hydrophilic inorganic phases. From XRD analysis of the blend composites (Fig. 2(b) and S7†) with modified MMT, the peaks for gallery spacing are observed

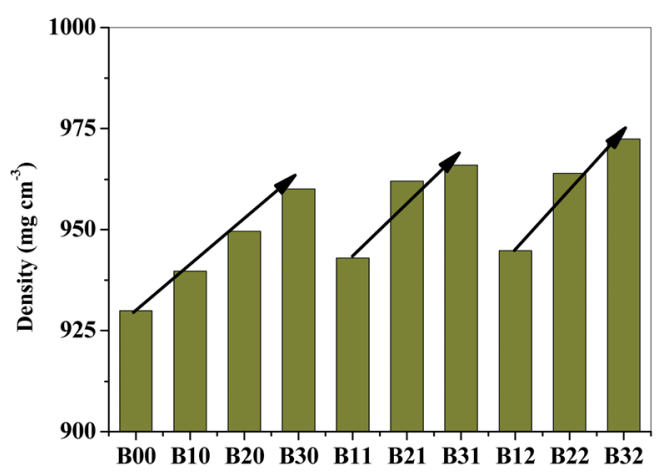

Fig. 3 Density profiles for neat PEMA, PEMA/EVOH blends and PEMA/ $\mathrm{EVOH} / \mathrm{MMT}$ composites. 
at $2 \theta<1.5^{\circ}$. This suggests the spacing between the modified MMT platelets is $\geq 60 \AA$ in these composites. This increase in gallery spacing suggests that the processing techniques used were effective for achieving good barrier materials with increased diffusion path length ${ }^{67}$ for the penetrant. The peaks observed at $21.3,23.7$ and $44.6^{\circ}$ correspond to the presence of [110], [200] and [121] crystal planes of the crystalline ethylene content in the Surlyn ionomer.

Differential scanning calorimetric (DSC) characterization for the neat, blend and composite films are shown in Fig. 4(a) and (b), s8(a) and (b). $\dagger$ The self healing mechanism of Surlyn is related to the reversible ionic aggregate formation when supplied with thermal energy. The order-disorder transition temperatures $\left(T_{\mathrm{o}}\right)$ where the ionic aggregates become disordered $^{68}$ during heating define the self healing capacity of Surlyn. The value of $T_{\mathrm{o}}$ decreased by $\sim 0.6^{\circ} \mathrm{C}$ with the addition of $\mathrm{EVOH}$ to Surlyn and it increased with the addition of modified MMT to the blend. This suggests the self healing capacity of PEMA/ EVOH blend is retained with the addition of filler. The peaks observed in the DSC thermogram correspond to the melting temperatures of all the blend composite films and were in the range 97.1 to $97.9{ }^{\circ} \mathrm{C}$ and did not show any significant variation (Table 1). The thermal stability of these composites was determined from thermo-gravimetric analysis (Fig. S9(a) and (b) $\dagger$ and Table 1). It can be observed that the onset temperature of
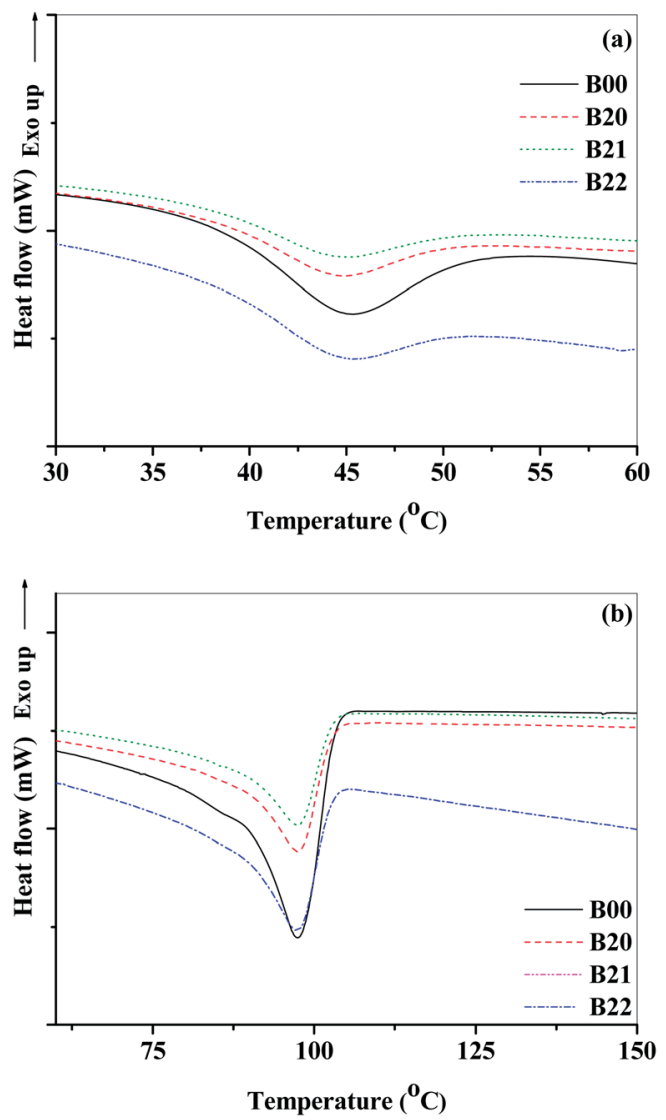

Fig. 4 DSC thermograms for B00, B20, B21 and B22 compositions (a) order-disorder transition temperatures observed during first heating cycle (b) PEMA melting peaks from the second heating cycle. degradation decreased with the addition of EVOH as well as modified MMT. However, all the compositions were stable up to $350{ }^{\circ} \mathrm{C}$ with less than $5 \mathrm{wt} \%$ degradation.

For the application of organic device encapsulation, it is required for the barrier material to possess flexibility and good tensile properties in order to sustain long term wear of the devices. ${ }^{69}$ It is observed from the tensile studies (Fig. 5(a) and S10(a) $\dagger$ and Table 1) that the modulus of elasticity increased with the addition of EVOH to PEMA and decreased with increasing modified MMT content in the blend. The elongation at break decreased in the blend and composite films, which could be due to the restricted flexibility because of the interactions with EVOH and modified MMT. However, all the films were flexible $(>50 \%)$. The ultimate tensile strength increased up to $10 \mathrm{wt} \%$ addition of $\mathrm{EVOH}$ and then decreased with further addition of EVOH. Therefore, the composite with $10 \mathrm{wt} \% \mathrm{EVOH}$ can be considered to be a mechanically optimized composition.

Most of the packed products from food to organic electronics are prone to degradation due to the incidence of UV radiation. Based on the UV-visible spectroscopic analysis (Fig. 5(b) and S10(b) $\dagger)$, it can be observed that the blend and composite films have lower UV transmission compared to B00. Therefore, they can shield from UV radiation and thus are suitable for UV resistant applications. The visible light transparency of all the composite films is lower than that for neat PEMA. However, these films are transparent up to $50 \%$ in the near IR and visible region and are resistant to the UV radiation.
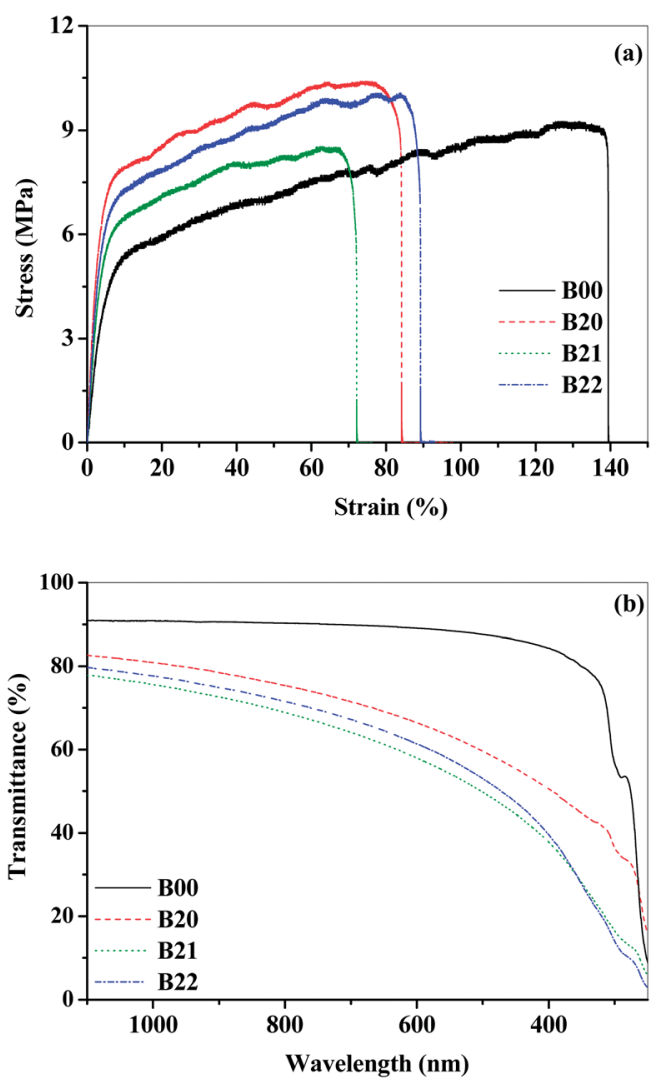

Fig. 5 (a) Tensile analysis and (b) UV-visible transparency for the neat, blend and composite films. 


\subsection{Barrier properties}

From the calcium degradation test, the OTR through the films was calculated and shown in Fig. 6(a) and S11(a). $\dagger$ With the addition of 5, 10 and $20 \mathrm{wt} \%$ of EVOH to PEMA, the OTR of B10, B20, B30 decreased by 1.4, 2.0 and 3.3 times the OTR for B00 (neat Surlyn), respectively. The diffusivity of $\mathrm{O}_{2}$ beads determined from DPD simulations (Fig. 7(a) and S12(a) $†$ ), for B10, $\mathrm{B} 20$ and B30 compositions, decreased the diffusivity by 1.2, 1.6 and 2 times relative to that of B00. Thus the results obtained by simulations nearly match that obtained experimentally. The molecular interactions in the composite hold the polymer chains in dense packing, reducing the diffusivity of oxygen molecules, as observed from DPD simulations based on the non bonded energy interactions between particles. The addition of MMT to the blend of PEMA/EVOH (B20, B30) further reduced the OTR of the composite blends (B21, B22, B32) by 25 times. The diffusivity of $\mathrm{O}_{2}$ beads in the composite blends decreased by only about 3.5 times compared to the blend diffusivities based on DPD simulation studies. This indicates that the relative reduction in permeabilities determined from experiments do not match with the relative reduction in diffusivities of $\mathrm{O}_{2}$ beads determined from simulations in the composite blends. This is because of the tortuous pathway provided by nano-clay to the blends for the incoming oxygen molecules was not considered in the simulations.

The WVTR through the barrier films was determined from CRDS based permeability setup as shown in Fig. 6(b) and
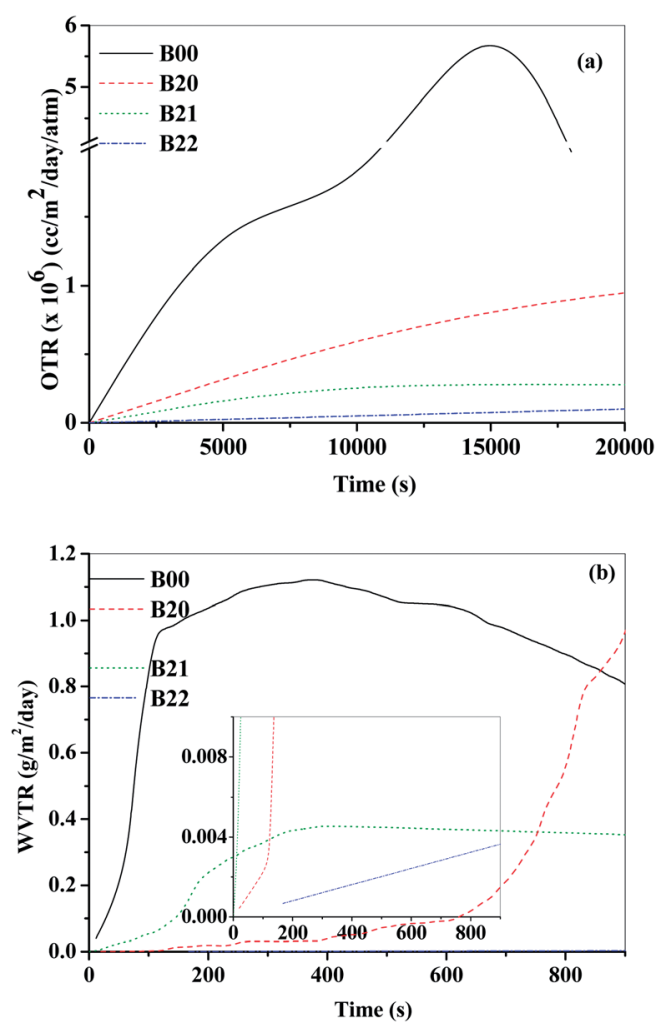

Fig. 6 Values for the neat, blend and composite films determined (a) OTR from calcium degradation test (b) WVTR from CRDS based permeability setup.
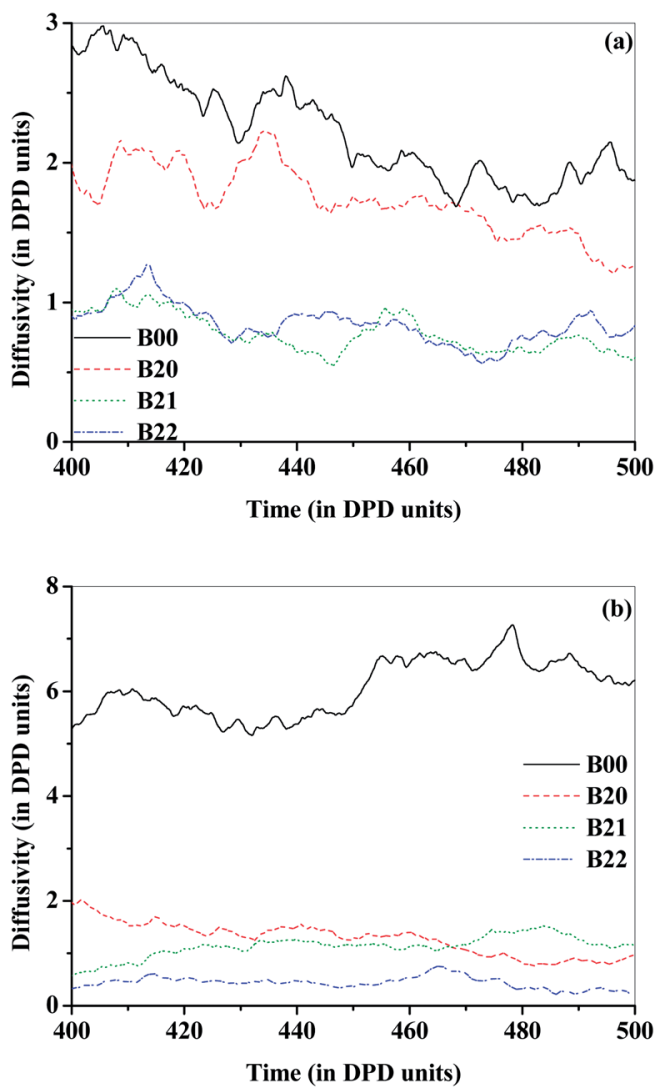

Fig. 7 Diffusivities of (a) $\mathrm{O}_{2}$ and (b) $\mathrm{H}_{2} \mathrm{O}$ beads through the neat, blend and composite films over the 400-500 DPD time units from the scaled DPD simulations.

S11(b). $\dagger$ With the addition EVOH to Surlyn, the reduction in WVTR for the blends B20 and B30, was observed to be 8 and 15 times, respectively, when compared with B00. The diffusivity of $\mathrm{H}_{2} \mathrm{O}$ beads in B20 and B30 determined from DPD simulations (Fig. 7(b) and S12(b) $\dagger$ ), decreased by 4.5 and 6.5 times the diffusivity in B00, respectively. The reduction in diffusivity of water molecules in the case of blend system can be attributed to the reduction in free volume and mobility of the polymeric chains due to the interactions between EVOH and PEMA. With the addition of modified MMT to the blends (B20, B30), the WVTR further decreased by $\sim 12$ times for the composite blends (B21, B22, B32). The diffusivities of $\mathrm{H}_{2} \mathrm{O}$ beads (Fig. 7(b) and $\mathrm{S} 12(\mathrm{~b}) \dagger)$. from DPD simulations in the B21, B22 and B32 compositions, decreased by $\sim 2$ to 2.5 times the diffusivities in their respective blends (B20 and $\mathrm{B} 30$ ). The relative reduction in diffusivity observed from simulations do not match with experimental values due to the presence of tortuous path as discussed earlier. This relative reduction in the diffusivity with respect to that in the neat PEMA system refers to the increase in constraint for the diffusing molecule through the composite due to the inter-molecular interactions from the embedded EVOH and modified MMT components in PEMA.

Based on the simulations for diffusivities of water and oxygen molecules, it is clear that the simulations are reasonably able to predict the decrease in diffusivities for the blends (B20, B30) but not for blend composites (B21, B22, B31, B32) with 

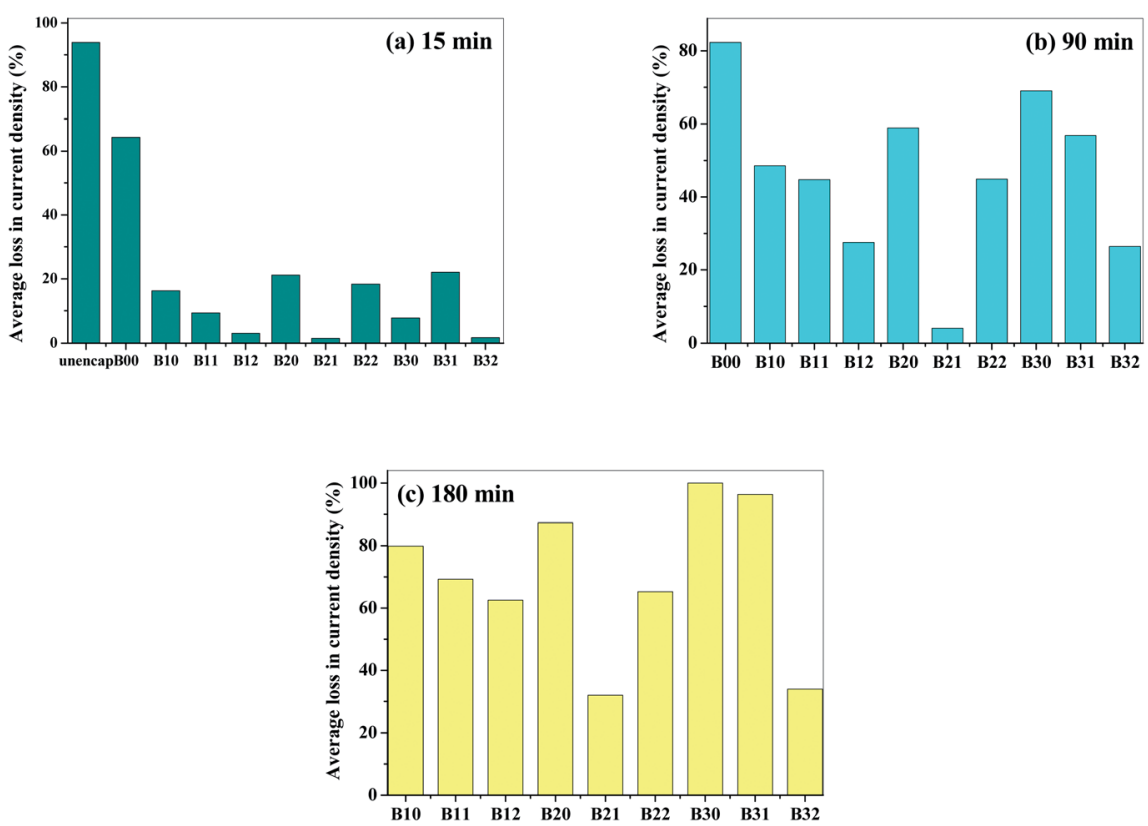

Fig. 8 Accelerated ageing studies at $95 \% \mathrm{RH}$ and $35{ }^{\circ} \mathrm{C}$ for encapsulated and non encapsulated organic Schottky structured devices after (a) 15 min (b) 90 min and (c) $180 \mathrm{~min}$.

modified MMT. This relative difference in experimental and simulation results, due to the effect of tortuosity induced with the addition of nano-clays to the blends is about $\sim 7$ times. Since the interaction parameters were calculated using energies from MD simulations, the diffusivity values determined from DPD simulations were purely based on non bonded molecular interactions which include Coulombic/electrostatic and van der Waals interactions between the components of the system. However, it is apparent that the composite system of PEMA/ EVOH/modified MMT can be considered as a complex interacting nanocomposite system from the observed reduction in diffusivities of oxygen and water molecules. From water vapor sorption studies (Table 1), with addition of $\mathrm{EVOH}$ as well as modified MMT, the reduction in the percent of water vapor sorbed by the barrier film was observed. For the composites, B22 and B32, the absorption of water vapor was much lower than $0.01 \%$. Therefore, the permeability, diffusion and sorption studies indicate the efficacy of the fabricated material as a good gas barrier material.

\subsection{Accelerated weathering studies}

The $J-V$ characteristics (Fig. S13 $\dagger$ ) for all the encapsulated Schottky structured, organic devices were measured before and after accelerated aging, $t \approx 0,15$, and $180 \mathrm{~min}$. The accelerated aging conditions were at $95 \% \mathrm{RH}$ and at $35{ }^{\circ} \mathrm{C}$. The loss in the device performance at these conditions will be roughly 2 orders higher than the loss in device performance that would be observed at $35 \% \mathrm{RH}$ and $25{ }^{\circ} \mathrm{C} .{ }^{23}$ The average device performance after accelerated aging was determined using the following, from eqn (4). In eqn (4), $I_{\mathrm{o}}$ and $I$ represent the initial current and current at time $t$. The $\%$ loss in device performance $(\Delta)$ is the average of $\Delta$ over 0 to $1 \mathrm{~V}$.

$$
\Delta=\frac{I_{\mathrm{o}}-I}{I_{\mathrm{o}}} \times 100
$$

The loss in device performance at various time periods is given in Fig. 8(a)-(c). It can be observed that after 15 min of accelerated ageing, the non-encapsulated device lost its performance completely $(\sim 100 \%)$ and the device encapsulated with neat Surlyn (B00) film lost about $65 \%$ of its performance while the devices encapsulated with B21 and B32 films lost only up to $5 \%$ of their performance. The devices encapsulated with B21 and B32 lost only 30\% even after $3 \mathrm{~h}$ of accelerated aging. This suggests that these composite films are capable of increasing the life time of the organic device by over an order of magnitude under accelerated conditions. This indicates the potential of the encapsulants to protect the device and can be used for packaging applications that require high barrier to oxygen or water vapor.

\section{Conclusions}

Surlyn ionomer blend nanocomposites were fabricated using Surlyn, EVOH and modified MMT. The nano-clays were ensured to be exfoliated in the Surlyn matrix by initially dispersion in EVOH. The addition of modified MMT to this blend system results in a highly interacting complex blend nanocomposite due to the favorable electrostatic and hydrogen bond interactions. A decrease in water vapor permeation was observed with increasing EVOH as well as modified MMT in the Surlyn matrix. The oxygen barrier properties were determined from calcium degradation test. The CRDS based permeability determination method has been successfully used for determining WVTR in this work. The WVTR decreased by about two orders of magnitude through the composite compared to that through 
neat Surlyn. Molecular dynamics simulations were used to determine the binary interaction energies between the components of the system. These energies were further used for scaling to macro level by hierarchical modeling of the blend composite system to indicate the effect of molecular interactions on the diffusivity of water and oxygen molecules through the composite system. The accelerated aging studies confirm that these Surlyn blend composites are effective as encapsulants in increasing the device life times by more than an order of magnitude. Therefore, the synthesized blend composites of Surlyn, EVOH and modified MMT were characterized both experimentally and theoretically to observe the effect on permeabilities of oxygen and water vapor through the materials and found to be suitable for flexible packaging applications. Moreover, these composites can be used as an inter-layer in multilayered film to further increase the barrier property.

\section{Acknowledgements}

We acknowledge the financial support for this work partially from and in part from DST no. SR/S3/ME/022/2010-(G) and from US-India Partnership to Advance Clean Energy-Research (PACER) for the Solar Energy Research Institute for India and the United States (SERIIUS). It is funded by the U.S. Department of Energy (Office of Science, Office of Basic Energy Sciences, and Energy Efficiency and Renewable Energy, Solar Energy Technology Program, under Subcontract DE-AC36-08GO28308 to the National Renewable Energy Laboratory, Golden, Colorado) and the Government of India, through the Department of Science and Technology under Subcontract IUSSTF/JCERDC-SERIIUS/ 2012 dated 22nd November 2012.

\section{Notes and references}

1 M. O. Reese, A. M. Nardes, B. L. Rupert, R. E. Larsen, D. C. Olson, M. T. Lloyd and N. Kopidakis, Adv. Funct. Mater., 2010, 20, 3476-3483.

2 H. Hintz, H. J. Egelhaaf, L. Luer, J. Hauch, H. Peisert and T. Chasse, Chem. Mater., 2010, 23, 145-154.

3 K. Norrman, S. A. Gevorgyan and F. C. Krebs, ACS Appl. Mater. Interfaces, 2009, 1, 102-112.

4 G. Dennler, C. Lungenschmied, H. Neugebauer, N. S. Sariciftci and A. Labouret, J. Mater. Res., 2005, 20, 3224-3233.

5 K. Norrman, N. B. Larsen and F. C. Krebs, Sol. Energy Mater. Sol. Cells, 2006, 90, 2793-2814.

6 F. C. Krebs, Sol. Energy Mater. Sol. Cells, 2006, 90, 3633-3643.

7 G. Dennler, C. Lungenschmied, H. Neugebauer, N. S. Sariciftci, M. Latreche, G. Czeremuszkin and M. R. Wertheimer, Thin Solid Films, 2006, 511-512, 349-353.

8 A. A. Dameron, S. D. Davidson, B. B. Burton, P. F. Carcia, R. S. McLean and S. M. George, J. Phys. Chem. C, 2008, 112(12), 4573-4580.

9 P. F. Carcia, R. S. McLean, M. H. Reilly, M. D. Groner and S. M. George, Appl. Phys. Lett., 2006, 89, 031913-031915.

10 H. Aziz, Z. Popovic, C. P. Tripp, N. X. Hu, A. M. Hor and G. Xu, Appl. Phys. Lett., 1998, 72, 756-758.
11 H. C. Langowski, U. Moosheimer, W. Peukert and M. Hanika, Chem. Eng. Technol., 2003, 26, 605-614.

12 S. Gupta, S. Seethamraju, P. C. Ramamurthy and G. Madras, Ind. Eng. Chem. Res., 2013, 52, 4383-4394.

13 S. Gupta, P. C. Ramamurthy and G. Madras, Ind. Eng. Chem. Res., 2011, 50, 6585-6593.

14 S. Gupta, S. Seethamraju, K. A. Varman, P. C. Ramamurthy and G. Madras, RSC Adv., 2012, 2, 11536-11543.

15 J. Gaume, C. Taviot-Gueho, S. Cros, A. Rivaton, S. Therias and J. L. Gardette, Sol. Energy Mater. Sol. Cells, 2012, 99, 240-249.

16 J. Ravichandran, A. G. Manoj, J. Liu, I. Manna and D. L. Carroll, Nanotechnology, 2008, 19, 5712.

17 H. Yusei, Y. Toshimune, N. Shunsuke and K. Yoshihiro, Polymer Membranes for Gas and Vapor Separation, 1999, vol. 2, pp. 194-214.

18 B. D. Freeman and J. H. Anita, Free Volume and Transport Properties of Barrier and Membrane Polymers, in Structure and Properties of Glassy Polymers, 1999, pp. 306-325.

19 Y. Huang and D. R. Paul, Ind. Eng. Chem. Res., 2007, 46, 2342-2347.

20 A. Eisenberg and M. Rinaudo, Polym. Bull., 1990, 24, 671.

21 A. Eisenberg, B. Hird and R. B. Moore, Macromolecules, 1990, 23, 4098-4107.

22 S. Seethamraju, P. C. Ramamurthy and G. Madras, ACS Appl. Mater. Interfaces, 2013, 5, 4409-4416.

23 S. Seethamraju, P. C. Ramamurthy and G. Madras, RSC Adv., 2013, 3, 12831-12838.

24 Test Method for Water Vapor Transmission Rate Through Plastic Film and Sheeting Using a Modulated Infrared Sensor, ASTM F1249-06, The American Society for Testing and Materials, 2011.

25 C. Charton, N. S. M. Fahland, A. Hollander, A. Wedel and K. Noller, Thin Solid Films, 2006, 502, 99-103.

26 A. A. Dameron, M. O. Reese, T. J. Moriconie and M. D. Kempe, Photovoltaics International, 2010, 9, 121-130, NREL Report no. JA-520-46476.

27 K. C. O'Brien, W. J. Koros, T. A. Barbari and E. S. Sanders, J. Membr. Sci., 1986, 29, 229-238.

28 Standard Test Methods for Water Vapor Transmission of Materials, ASTM E96/E96M - 12, Annual Book of ASTM Standards, The American Society for Testing and Materials, vol. 04.06.

29 M. D. Kempe, M. O. Reese and A. A. Dameron, Rev. Sci. Instrum., 2013, 84, 025109-025110.

30 S. R. Taylor, IEEE Trans. Electr. Insul., 1989, 24, 787-806.

31 P. Renucci, L. Gaudart, J. P. Petrakian and D. Roux, Phys. Rev. B: Condens. Matter Mater. Phys., 1982, 26, 5416-5425.

32 D. K. Michael, O. R. Matthew and A. D. Arrelaine, Rev. Sci. Instrum., 2013, 84, 025109-025118.

33 P. C. Ramamurthy, S. Gupta and G. Madras, IPEC 137/2012 1651/CHE/2012, 2012.

34 Q. H. Zeng, A. B. Yu and Q. G. Lu, Prog. Polym. Sci., 2008, 33, 191-269.

35 P. Sabrina and F. Maurizio, Chem. Eng. Commun., 2003, 190, 1267-1292.

36 T. Hisao and O. Keiji, J. Chem. Phys., 1990, 92, 5643-5652. 
37 E. Tocci, D. Hofmann, D. Paul, N. Russo and E. Drioli, Polymer, 2001, 42, 521-533.

38 S. G. Charati and S. A. Stern, Macromolecules, 1998, 31, 55295535.

39 P. C. LeBaron, Z. Wang and T. J. Pinnavaia, Appl. Clay Sci., 1999, 15, 11-29.

40 K. S. Rhutesh, D. L. Hunter and D. R. Paul, Polymer, 2005, 46, 2646-2662.

41 J. H. Choi, Y. M. Kim, Y. W. Park, J. W. Huh, B. K. Ju, I. S. Kim and H. N. Hwang, Rev. Sci. Instrum., 2007, 78, 064701064705.

42 Z. Piotr and R. N. Zare, J. Chem. Phys., 1995, 102, 2708-2717.

43 R. D. van Zee, J. T. Hodges and J. P. Looney, Appl. Opt., 1999, 38, 3951-3960.

44 W. B. Kenneth and A. B. Marianna, Introduction to CavityRingdown Spectroscopy, in Cavity-Ringdown Spectroscopy, ACS Symposium Series, 1999, vol. 720, pp. 7-19.

45 H. Sun, P. Ren and J. R. Fried, Comput. Theor. Polym. Sci., 1998, 8, 229-246.

46 B. Mehlig, D. W. Heermann and B. M. Forrest, Phys. Rev. B: Condens. Matter Mater. Phys., 1992, 45, 679-685.

47 M. Levitt and S. Lifson, J. Mol. Biol., 1969, 46, 269-279.

48 O. Ermer, Struct. Bonding, 1976, 27, 161-211.

49 R. Fletcher and C. M. Reeves, Comput. J., 1964, 7, 149-154.

50 N. Metropolis, A. W. Rosenbluth, M. N. Rosenbluth, A. H. Teller and E. Teller, J. Chem. Phys., 1953, 21, 1087-1092.

51 C. Ioana, B. Mario and A. G. William, J. Phys. Chem. B, 2007, 111, 3151-3166.

52 S. Nose, Prog. Theor. Phys. Suppl., 1991, 103, 1-46.
53 H. J. C. Berendsen, J. P. M. Postma, W. F. van Gunsteren, A. DiNiola and J. R. Haak, J. Chem. Phys., 1984, 81, 3684-3690. 54 J. P. Perdew, K. Burke and M. Ernzerhof, Phys. Rev. Lett., 1996, 77, 386-389.

55 B. Delley, J. Phys. Chem. A, 2006, 110, 13632-13639.

56 S. I. Tsipursky and V. A. Drits, Clay Miner., 1984, 19, 177-193.

57 N. T. Skipper, F. R. C. Chang and G. Sposito, Clays Clay Miner., 1995, 43, 285-293.

58 F. Maurizio, F. Marco and P. Sabrina, Fluid Phase Equilib., 2003, 212, 315-329.

59 M. L. Connolly, Science, 1983, 221, 709-713.

60 S. Giulio, P. Paola, F. Maurizio and P. Sabrina, J. Phys. Chem. $B, 2007,111,2143-2151$.

61 R. D. Groot and P. B. Warren, J. Chem. Phys., 1997, 107, 44234435.

62 J. Madejova, Vib. Spectrosc., 2003, 31, 1-10.

63 S. Kutsumizu, H. Hara, H. Tachino, K. Shimabayashi and S. Yano, Macromolecules, 1999, 32, 6340-6347.

64 K. Han and H. L. Williams, J. Appl. Polym. Sci., 1991, 42, 1845-1859.

65 M. M. Coleman, J. Y. Lee and P. C. Painter, Macromolecules, 1990, 23, 2339-2345.

66 A. S. David, R. S. Paul and A. M. Kenneth, J. Appl. Polym. Sci., 2000, 77, 2832-2844.

67 L. Chunsheng and W. M. Yiu, Phys. Rev. Lett., 2005, 95, 088303-088306.

68 K. Tadano, E. Hirasawa, H. Yamamoto and S. Yano, Macromolecules, 1989, 22, 226-233.

69 L. Jay, Mater. Today, 2006, 9, 38-45. 